\title{
The influence of ultrasounds on the process of uranium desorption
}

\author{
Eugenia Panturu ${ }^{1}$, Antoneta Filcenco-Olteanu ${ }^{1,{ }^{*}}$, Aura Daniela Radu $^{1}$, and Marius Zlagnean ${ }^{1}$ \\ ${ }^{1}$ E1Research \& Development National Institute for Metals and Radioactive Resources, 70 Carol I Bvd., 020917, Bucharest, Romania
}

\begin{abstract}
In the present paper, we have studied the intensification of the desorption process of the complex anions of uranium $\mathrm{U}(\mathrm{VI})$, from ion exchange resins under the action of the ultrasonic field. The dynamics of uranium desorption from the anionic resins Purolite A600U/3472 and PM 611 was analyzed, both in standard conditions and with ultrasounds. The use of ultrasounds leads to the substantial growth of desorption kinetics and of the uranium recovery degree. The tests for stability of the resin grains size, mechanical resistance and the capacity of loading with uranium, after the repeated action of the ultrasounds field, emphasized the physical-chemical stability of resins used in the experiment (loading capacity of untreated resin $30.36 \mathrm{mgU} / \mathrm{g}$ resin and treated in continuous ultrasonic field $30.85 \mathrm{mgU} / \mathrm{g}$ resin).
\end{abstract}

\section{Introduction}

The industrial application of ionic exchange is widespread in areas starting from water softening, wastewater treatment and analytical chemistry to the purification of pharmaceutical products and of precious and radioactive metals [1-4]. The use of anions-exchange resins for uranium recovery from uranium-containing solutions is possible if the resin provides a high selectivity for uranium complexes, allows the desorption of the retained complex with simple agents, which give rich elutes and has the ability of multiple reuse [5-11].

As the ion desorption from the resin is the reverse process of adsorption, the physical and chemical factors that inhibit adsorption will favor desorption and, respectively, those who favor adsorption will inhibit desorption. Although desorption can be improved by increasing the temperature or by using concentrated extractants solutions, these measures may not be efficient from the costs' point of view. The use of ultrasounds as a means of enhancement of property transfer processes is reported in the specialty literature since the 1960 s up to the present.

Thus, the Russian researchers [12] have shown that both the ultrasonic agitation and the mechanical agitation can accelerate the ionic exchange equilibrium, as the authors noticed the ultrasonic agitation is much more efficient than the mechanical one. Later on, it was noticed that the ionic-exchange equilibrium reached by applying an ultrasounds field lasts more than the one obtained in the case of mechanical agitation. Cheng and Wang [13] claimed that energy of the shockwave that occurs when the cavitation bubble collapses would interrupt film diffusion of the ions. Other studies [14] have shown that in the presence of an ultrasonic field, the capacity of ionexchange resin increases with approx. $15-20 \%$, and the rate of adsorption likewise increases. In other studies, [15, 16] it has been proved that the ultrasounds' effect is not limited only to the surface layer of the resin particle. In the presence of an ultrasound field, during cavitation a side effect that leads to an exposure of micro pores from the sorbent particles is produced. At the same time, the pressure pulsation induced by cavitation can facilitate the penetration of the solution in the micro capillaries relatively inaccessible from the sorbent particle.

Liu et al. [17], Mukherjee et al. [18] have demonstrated that ultrasonication can dislocate the organic matter adsorbed on a specific area of aquatic sediments and, consequently, to significantly increase the bioavailability of the sorbent.

Newman et al. [19] have conducted similar studies on granulated pieces of brick impregnated with copper oxide as a model for the decontamination of polluted soils. They noticed a decrease by $40 \%$ of the copper content through the washing of the impregnated pellets with a stream of water, in an ultrasonic tank at a frequency of $20 \mathrm{kHz}$.

Qin et al [20] investigated the effect of ultrasound on the desorption of phenol from impregnated resins and noticed. That ultrasound had "spot energy effects" which would enhance the process. Likewise, Rege et al. [21] showed that ultrasounds can lead to the increase of phenol adsorption rate from activated carbon and polymeric resins.

Küncek and Sener [22] used ultrasonication as a pretreatment process to increase the adsorption capacity of sepiolite, a natural clay-based adsorbent, used to remove the methylene blue. The physical effect of the ultrasonication $(20 \mathrm{kHz}, 5$ hours) lead to a significant increase of the sepiolite specific surface area, which led to a higher retention capacity.

Recently [23] an experimental method has been developed for the efficient removal of methylene blue in

*Corresponding author: antonetafilcenco@yahoo.ro 
the presence of ultrasounds $(40 \mathrm{kHz})$, using the process of adsorption on activated coal impregnated with gold nanoparticles.

In recent years the research regarding the application of ultrasounds in hydrometallurgy, in dissolution operations [24-37], ionic exchange [38-47], and solvent extraction [48-53] has expanded.

Balasubrahmanyam et. al [54] have been performed experiments for leaching of uranium from $\mathrm{MgF}_{2}$ (byproduct from the uranium ore recovery process) in presence and in absence of ultrasound, using various conditions of leach acid concentration, different energy dissipation rates and different $\mathrm{MgF}_{2}$ particle size distribution. It was obtained that the overall recovery has been increased by the application of ultrasonication and the main advantage of using ultrasound was the decreasing of the leaching operation time.

Kalsi et. al [55] have been studied the recovery of uranium form fluoride matrix under the influence of ultrasonication $(22 \pm 3 \mathrm{kHz}$ and $150 \mathrm{~W})$ and it was obtained a $76-91 \%$ removal of uranium form $\mathrm{MgF}_{2}$ slag. The major advantages in this case are minimizing labor, remotisation of operations to reduce exposure, use of less nitric acid and the reduction in the reaction time.

Research on sono-chemical leaching of uranium [56] in nitric acid and sulfuric acid media has been carried out to understand the effect of ultrasonication on leaching process. Thus, it has been observed that the leaching rate under the influence of ultrasound is higher with low acid concentration of nitric acid, and it is high at a high leach acid concentration in case of sulfuric acid, compared to mechanical agitation, due to the faster rate in presence of ultrasonication of oxidative conversion mechanism of uranium tetravalent to hexavalent form.

Bikram et. al [57] conducted studies regarding the application of ultrasonication in density determination of uranium loaded organic phase in solvent extraction. Their method using dual frequency based ultrasound density measurement of uranium loaded organic samples in solvent extraction process can be used for critical density determination at extraction and reprocessing in the fuel cycle.

Hamadaoui and Naffrechoux [58] in their studies have been investigate the mechanism of ultrasonically enhanced desorption of 4-chlorophenol from granular activated carbon. Experiments of desorption were made in absence and in presence of ultrasonication at $516 \mathrm{kHz}$ of different intensities and the conclusion was that the use of ultrasound field improves both the amount and the rate of desorption. Desorption increases with increasing temperature and ultrasound intensity, the mechanism of ultrasonically enhanced desorption in due both to the thermal and non-thermal effects of ultrasound field.

Korean researchers [59], studying the batch absorption of uranium from acidic solutions on ion-exchange resins, have discovered that when applying simultaneously the mechanical agitation and an ultrasonic field, the uranium adsorption speed on the ion-exchange resin increases because of both the increase of collision frequency, and the mixing intensification due to cavitation.
These studies suggest that ultrasonic radiation can be an effective way to improve the adsorption/desorption of ion species from the ion-exchange resins.

The aim of the research presented in this paper is to determine how ultrasounds help improve uranium desorption from ion-exchange resins type Purolite A 600U/3472 and PM 611.

\section{Experimental}

\subsection{Reagents and materials}

The reagents used were chemically or analytically pure (to perform the analysis) and used without additional treatment. The synthetic uranium solution was prepared from uranyl sulphate $\left(\mathrm{UO}_{2} \mathrm{SO}_{4}\right)$ in distilled water, and for the $\mathrm{pH}$ correction was used anhydrous sodium carbonate $\left(\mathrm{Na}_{2} \mathrm{CO}_{3}\right)$. The chemical composition of the synthetic solution is: $\mathrm{U}=35.37 \mathrm{mg} / \mathrm{L}, \mathrm{Na}_{2} \mathrm{CO}_{3}=3.18 \mathrm{~g} / \mathrm{L}, \mathrm{NaHCO}_{3}$ $=0.504 \mathrm{~g} / \mathrm{L}$ and $\mathrm{pH}=9.5$.

Uranium desorption was made by using a chloro sodic solution having the composition: $100 \mathrm{~g} / \mathrm{L}$ sodium chloride $(\mathrm{NaCl})$, and $10 \mathrm{~g} / \mathrm{L}$ sodium carbonate $\left(\mathrm{Na}_{2} \mathrm{CO}_{3}\right)$.

The resin Purolite A600U/3472, supplied by the company Purolite SA, Victoria, Romania (Purolite Co. Philadelphia, USA) is a strong basic anionite, with gel structure, specially designed for the recovery of soluble anionic complexes of uranium from acid or alkaline media. Structurally, this anionite is a polystyrene divinylbenzene polymer, with excellent mechanical integrity and resistance to stress.

Resin PM 611, provided by the company Suzhou Bojie Resin Technology Co. Ltd China,is a strong basic anionic exchanger, with a gel-type structure type 1, designed to separate the soluble anionic complexes of uranium in acidic or alkaline medium.

\subsection{Experimental methodology}

The resins were activated for the adsorption of uranium through sequential treatment with sodium hydroxide $(\mathrm{NaOH}) 4 \%$ and hydrochloric acid $(\mathrm{HCl}) 4 \%$, using Berzelius glasses and magnetic stirrer type IKA RH-KT/C (manufactured by WERKE, Germany); the resin washing was made with distilled water $(\mathrm{pH}=3-3.5)$ so that the resin remains in the $\mathrm{Cl}^{-}$form.

The initial adsorption process was carried out under dynamic conditions, adsorption - desorption cycles conducted in a fixed bed, in four identical glass columns, with a length of $12 \mathrm{~cm}$ and an inner diameter of $1.5 \mathrm{~cm}$ where were placed $5 \mathrm{~mL}(3.5 \mathrm{~g})$ resin (Purolite A600U /3472 and PM 611). The columns were provided at the ends with frits in order to prevent losses of resin through intromission in effluent. The uranium solution flow rate through the ion exchange resin was $5 \mathrm{BEV} / \mathrm{h}(\mathrm{BEV}=\mathrm{Bed}$ Equivalent Volume of resin in the column). After uranium loading, the resin was washed with water and stored for the desorption tests. It is considered that the resins are fully loaded when the uranium content in the effluent equals the influent concentration. The loading capacity of 
the Purolite A600U/3472 resin was $30.36 \mathrm{mgU} / \mathrm{g}_{\text {resin, }}$ while that of the PM 611 resin was $25.64 \mathrm{mgU} / \mathrm{g}_{\text {resin }}$.

Desorption was carried out both under standard conditions and in a continuous ultrasound system.

For carrying out the desorption tests in fixed bed in continuous ultrasound system, the column loaded with resin was immersed in the ultrasonic bath type Retsch UR1 (manufactured by Retsch GmbH, Germany), equipped with a high-frequency generator type PZT35 $\mathrm{kHz}$ and a power of $480 \mathrm{~W}$. In order to maintain the temperature of the ultrasonic bath to a value of approx. $20^{\circ} \mathrm{C}$, the bath water was changed continually with fresh tap water.

The supply with chloro-sodic solution necessary to the uranium desorption was carried out by means of a metering pump type 7521-47 (manufactured by Barington Bamant Co., USA). The chloro-sodic solution flow rate was $1 \mathrm{BEV} / \mathrm{h}(5 \mathrm{~mL} / \mathrm{h})$.

Uranium ion concentration in solutions was determined through the colorimetric solution, with the use of a UV-VIS CECIL 1011 spectrophotometer (manufactured by CECIL, Great Britain).

The mean momentary resin loading capacity with $\mathrm{U}$ (VI), $q_{i}$, was determined by difference between the amount of uranium in the initial and final solution, per volume of resin (equation 1) [60].

$$
q=\frac{\sum_{j=1}^{i} G_{v}\left(c_{u i n}-c_{u f j}\right) \tau_{j}}{M_{r}}
$$

where $c_{\text {uin }}$ is the uranium concentration of initial solution, $\mathrm{g} / \mathrm{L}, \quad c_{U f j}$ is the momentary uranium concentration at bed exit solution, $\mathrm{g} / \mathrm{L}, M_{r}$ is the mass of resin, g, and $G_{v}$ represent the volumetric flow rate of solution which traverse the resin bed $\left(\mathrm{G}_{\mathrm{v}}=25 * 10^{-3} \mathrm{~L} / \mathrm{h}\right)$.

The stability of the resin grains size to the repeated action of ultrasounds was established after a granulometric comparative analysis carried out with a set of vibrating bolters type Retsch AS 200 (manufactured by Retsch GmbH, Germany) with a loop size of $0.2,0.25 ; 0.5 ; 0.63 ; 0.8 ; 1$ and $2 \mathrm{~mm}$, and a SEM analysis (Scanning Electron Microscopy, Quanta 3 D FEG, FEI Company, USA). Before and after the ultrasonication (6 and 18 hours), the resin samples were filtered and dried at room temperature for 24 hours.

The determination of the resin beads' mechanical resistance was carried out through grinding for 10 minutes in a mill with porcelain balls with the following features: mill diameter $98 \mathrm{~mm}$, mill length $105 \mathrm{~mm}, 20$ porcelain balls of $15 \mathrm{~mm}$ diameter, 30 balls with a $9.5 \mathrm{~mm}$ diameter, total ball load weight $130 \mathrm{~g}$, mill speed $100 \mathrm{rpm}$. The swollen resin, in $\mathrm{Cl}^{-}$form, was placed on a bolter with 0.8 $\mathrm{mm}$ loops, and class $-0.8 \mathrm{~mm}$ was removed. $100 \mathrm{~cm}^{3}$ of the class $+0.8 \mathrm{~mm}$ was subjected to crushing. After the crushing, the resin is separated from the balls and placed on a bolter with a loops' diameter of $0.63 \mathrm{~mm}$. Fractions $\mathrm{A}(+0.63 \mathrm{~mm})$ and $\mathrm{B}(-0.63 \mathrm{~mm})$ are subjected to draining on a filtering cone with a G5 frit and is dried at room temperature for 24 hours. The fractions are weighed on an analytical balance type Precisa XT220A (manufactured by Precisa Gravimetrics AG Moosmattstrasse $32 \mathrm{CH}$ 8953 Dietikon). The mechanical resistance is expressed by equation 2 [28]:

$$
R_{m}=\frac{A}{A+B} \times 100
$$

\section{Results and discussion}

\subsection{The dynamics of uranium desorption from the anion-exchange resins Purolite A-600U/3472 and PM 611 without/with ultrasounds}

After loading the resin with uranium, it was subjected to the process of uranium desorption with chloro-sodic solution. Adsorption/desorption of uranium from carbonated solutions occurs according to equation 3 :

$4\left(\mathrm{R}^{+}-\mathrm{Cl}^{-}\right)+4 \mathrm{Na}^{+}+\left[\mathrm{UO}_{2}\left(\mathrm{CO}_{3}\right)_{3}\right]^{4-} \Leftrightarrow 4 \mathrm{R}^{+}-\left[\mathrm{UO}_{2}\left(\mathrm{CO}_{3}\right)_{3}\right]^{4-}+4\left(\mathrm{Na}^{+}-\mathrm{Cl}^{-}\right)$

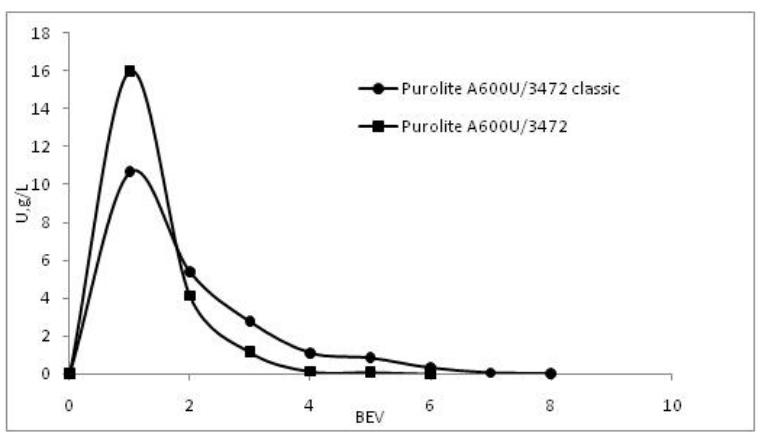

Fig. 1. Desorption isotherms of uranium fixed on Purolite A600U/3472 resin both in classic conditions and in the presence of ultrasonication.

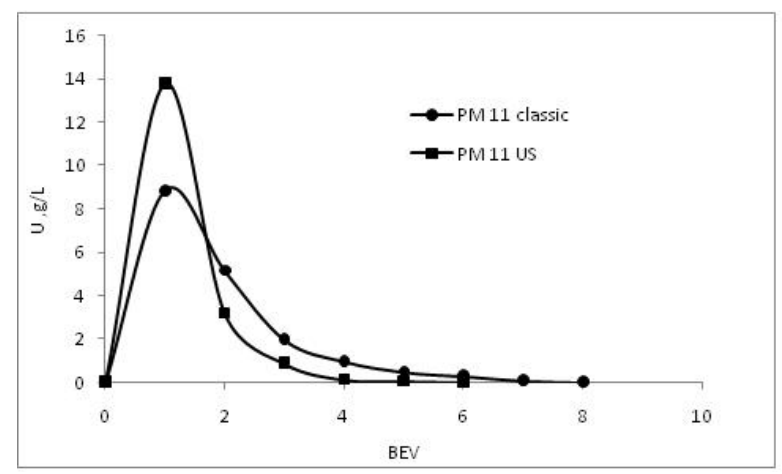

Fig. 2. The desorption isotherms of uranium fixed to the PM 611 resin under classic conditions and in the presence of ultrasonication.

For the comparison of the experimental results obtained and the highlight of the positive effects of ultrasounds on the desorption process of uranium complex anions from the ion-exchange resin, desorption isotherms have been plotted (figure 1), both in classic 
conditions and with ultrasounds for the resin Purolite A600U/3472.

In Figure 2 are comparatively presented the desorption isotherms of uranium complex anions from resin PM 611 in classic conditions and with ultrasounds.

As can be noticed in the figures shown, the use of ultrasounds considerably improves desorption. While in the absence of ultrasounds the complete desorption from the two resin types (Purolite A600U/3472 and PM 611, respectively) is carried out with $8 \mathrm{BEV}$ of chloro-sodic solution, in their continuous presence throughout the process, the complete elution takes place with only $4 \mathrm{BEV}$ chloro-sodic solutions. The use of a smaller volume may be due to desorption intensification towards the end of the process, when the removal of uranium from the resin on the classic operation is carried out very slowly (4 BEVs are needed to remove the last $5-6 \%$ from uranium quantity.

The dynamics of uranium elution from Purolite A600U/3472 resin with and without ultrasounds is shown in Figure 3, and the dynamics of the uranium elution from PM 611 resin is shown in Figure 4.

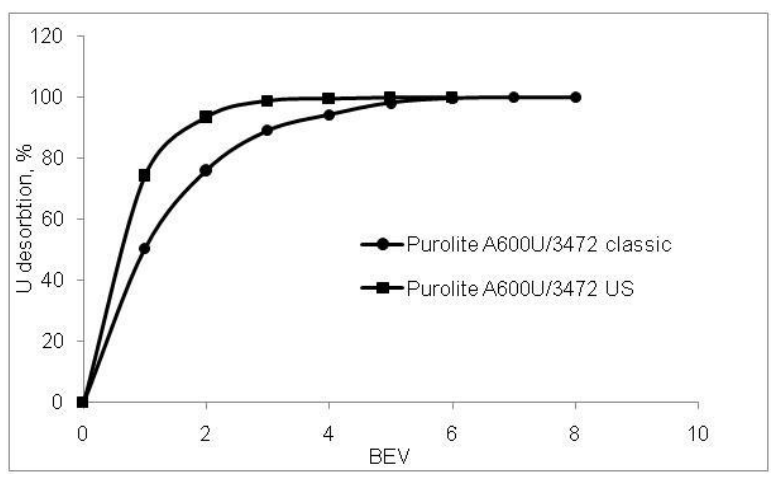

Fig. 3. Dynamics of uranium desorption from e Purolite A600U/3472 resin with and without ultrasonic field.

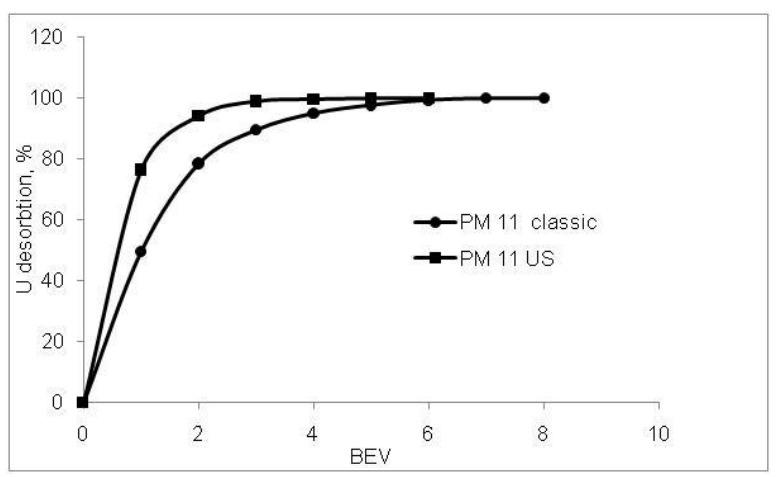

Fig. 4. Dynamics of uranium desorption from the PM611 resin with and without ultrasonic field.

The analysis of uranium desorption dynamics shows the fact that under classic conditions the uranium is desorbed from the two resin types in a percentage of $99 \%$ in a volume of $7 \mathrm{BEV}$ chloro-sodic solution, whereas under the continuous ultrasounds' action this happens with a volume of $3 \mathrm{BEV}$. The difference between the two resins consists in the uranium content in the effluent and the recycled uranium percentage, which is in favor of the resin Purolite A6000 U/ 3472. In Table 1 are shown both the effluent composition that is obtained (eluate) and the percentage of recycled uranium from the rest of obtained eluate.

Table 1. Uranium content in effluent function of desorption conditions.

\begin{tabular}{|c|l|c|c|c|}
\hline $\begin{array}{c}\text { Resin } \\
\text { type }\end{array}$ & $\begin{array}{c}\text { Desorption } \\
\text { conditions }\end{array}$ & $\begin{array}{c}\text { No. } \\
\text { BEV }\end{array}$ & $\begin{array}{c}\text { Effluent } \\
\text { uranium } \\
\text { content, } \\
\text { g/L }\end{array}$ & $\begin{array}{c}\text { Recycled } \\
\text { uranium, } \\
\text { \% }\end{array}$ \\
\hline \multirow{2}{*}{$\begin{array}{c}\text { Purolite } \\
\text { A600U }\end{array}$} & Classic & 3 & 6.27 & 10.88 \\
\cline { 2 - 5 } & US & 3 & 7.09 & 1.07 \\
\hline \multirow{2}{*}{ PM611 } & Classic & 3 & 5.36 & 10.41 \\
\cline { 2 - 5 } & US & 3 & 5.95 & 1.03 \\
\hline
\end{tabular}

As a result of these experiments it was demonstrated the feasibility of using ultrasounds to enhance desorption of the uranium ions from the ion-exchange resins. In these experiments, particle diffusion and film diffusion are the rate determinant steps. Because ultrasounds produce acoustic vortices which cause micro turbulences both inside the particle pores and on the interface solid-liquid, these improve the desorption rate by increasing the rate of transport through diffusion in particle and in film, which leads to a high level of $U$ in the first 2-3 volumes, which are precipitated. The rest of up to 8 volumes (with low uranium level) will be recycled.

\subsection{Influence of ultrasounds on the physical features of resins Purolite A-600U/3472 and PM 611}

To establish the influence of ultrasounds on the physical properties of the two strongly basic anionic resins, stability tests and SEM analysis were conducted regarding the grains' size and mechanic resistance.

\subsubsection{Stability of the resin grain size}

Friable solids such as resin grains existing in an aqueous ultrasonated solution might be broken or eroded due to high pressure shock waves resulting from cavitations implosions.

In order to assess the integrity of polymeric resins subjected to the ultrasounds field, swollen resin samples are placed in a glass beaker immersed in the ultrasounds bath and ultrasonated for 6 and 8 hours, respectively.

In Figures 5 and 6 is shown the content evolution of the granulometric classes of interest $0-0.2 \mathrm{~mm}$; $0.8-1 \mathrm{~mm}$ and 1-2 $\mathrm{mm}$ for the two resins, depending on the length of the ultrasounds field. 


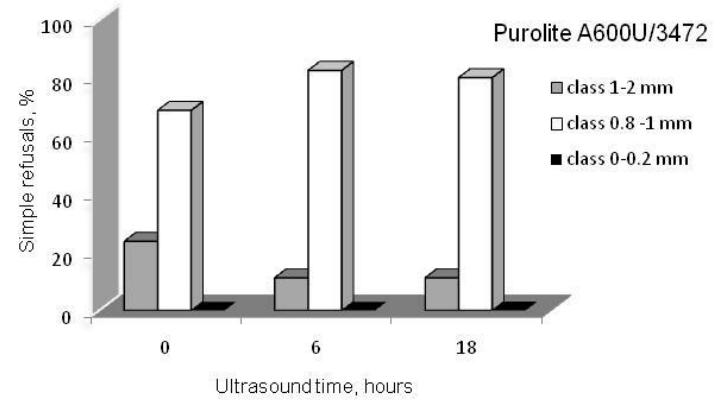

Fig. 5. Variation of particle size classes $1-2 \mathrm{~mm} ; 0.8-1 \mathrm{~mm}$ and $0-0.2 \mathrm{~mm}$ depending on the time in ultrasound field for Purolite $\mathrm{A} 600 \mathrm{U} / 3472$ resin.

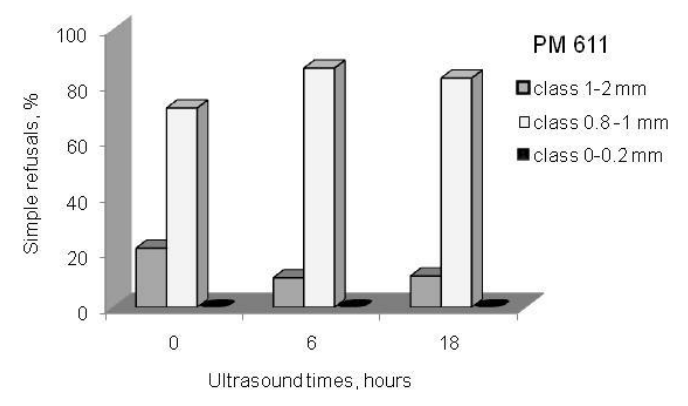

Fig. 6. The variation of particle size classes 1-2 mm; 0.8-1 mm and $0-0.2 \mathrm{~mm}$ depending on the time in ultrasound field of PM 611 resin.

Analyzing the results obtained, both for the Purolite A 600U/3472 resin and for the PM 611 resin is seen the fact that after the first 6 hours of ultrasonication, a decrease of content for the class 1-2 mm takes place, after which the granulometric characteristics remain constant.

\subsubsection{The stability of mechanical resistance of the resin grains}

Mechanical resistance, an essential characteristic (along with loading capacity of the resin with uranium) was established by the granulation process described in the experimental part. In the experiments carried out, resin fractions $\mathrm{A}(+0.63 \mathrm{~mm})$ and $\mathrm{B}(-0.63 \mathrm{~mm})$ were volumetrically determined right after sizing the milled resin 6 hours. The results obtained are shown in Table 2 .

From the data presented are determined the following:

- in the case of untreated resins, the loss in passing sieve of $0.63 \mathrm{~mm}$ were almost insignificant, of only 0.25 for the resin Purolite A600U/3472, respectively of $0.50 \%$ for resin PM 611;

- in the case of afterwards ultrasonicated resins for 18 hours, the loss in passing sieve of $0.63 \mathrm{~mm}$ were slightly larger than in the case of untreated resins, namely 2.50 in the case of resin Purolite 600U/3472, respectively $4.00 \%$ for resin PM 611;

- the degradation of resin PuroliteA600U/3472 is due to the uniform grain use; the grains that reached in passing sieve kept their spherical shape but not the size;

- during the milling of resin PM 611 the grains don't keep completely their spherical shape, in the water appear resin detached fragments resembling some "fluff" or "flakes";

- the mechanical resistance obtained for the two types of resins, in the two cases was:

- for the non-ultrasonated resin - $\mathrm{R}_{\mathrm{m}}=99.75 \%$ (Purolite $\mathrm{A} 600 \mathrm{U} / 3472) ; \mathrm{R}_{\mathrm{m}}=99.50 \%$ (PM611)

- for the ultrasonated resin for 18 hours $-R_{m}=97.50 \%$ (Purolite A600U/3472); $\mathrm{R}_{\mathrm{m}}=96.48 \%$ (PM611)

Table 2 The experimental results of the grinding test for 6 hours.

\begin{tabular}{|c|c|c|c|c|}
\hline \multirow[b]{2}{*}{ Resin } & \multicolumn{3}{|c|}{ Resin volume, $\mathrm{mL}$} & \multirow{2}{*}{$\begin{array}{l}\text { Loss relative to baseline } \\
\text { (cumulative passes, \%) }\end{array}$} \\
\hline & $\begin{array}{c}\text { Fraction A }+0.63 \\
\mathrm{~mm}\end{array}$ & $\begin{array}{l}\text { Fraction B } \\
-0.63 \mathrm{~mm} \\
\end{array}$ & $\mathbf{R}_{\mathrm{m}}, \%$ & \\
\hline $\begin{array}{l}\text { Purolite SGA600U/3472 } \\
\text { absence of ultrasound }\end{array}$ & 99.75 & 0.25 & 99.75 & 0.25 \\
\hline $\begin{array}{c}\text { Purolite SGA600U/3472 } \\
\text { presence of ultrasound } 18 \text { hours }\end{array}$ & 97.50 & 2.50 & 97.50 & 2.50 \\
\hline $\begin{array}{c}\text { PM611 } \\
\text { absence of ultrasound }\end{array}$ & 99.50 & 0.50 & 99.50 & 0.50 \\
\hline $\begin{array}{c}\text { PM 611 } \\
\text { presence of ultrasound } 18 \text { hours }\end{array}$ & 96.00 & 3.50 & 96.48 & 4.00 \\
\hline
\end{tabular}

\subsubsection{SEM analysis of resin granules}

SEM analysis imagines of the resins evaluated in this study, magnified from $60,000 \mathrm{X}$ to $2,000,000 \mathrm{X}$ are shown in Figures7 -12.

SEM analysis of the resins, after sonication showed that the Purolite A600U/3472 resin maintains its spherical shape, without modification of the surface (Figures 8 - 9), while resin PM11 after 6 hours of ultrasound is not spherical, it flattens the shape. That fact finds after 18 hours of sonication also (Figures 11-12).
The analysis of micro - compositional quality of samples analyzed is the spectral lines main $\mathrm{K} \alpha$ of each sample and the analysis of micro - compositional quantity thereof, presents the evidence in the detection limit of the machine, expressed as a percentage by mass (Wt \%) and the atomic percent (At \%). Initial values of granules for each type of resin is not identical but they are in controlled limits so small variations in the values appear in microcompositional analysis.

SEM analysis of the resin granules test results confirm the stability and mechanical strength of scale, being able to state that ultrasound does not affect the physicochemical properties of studied resins 

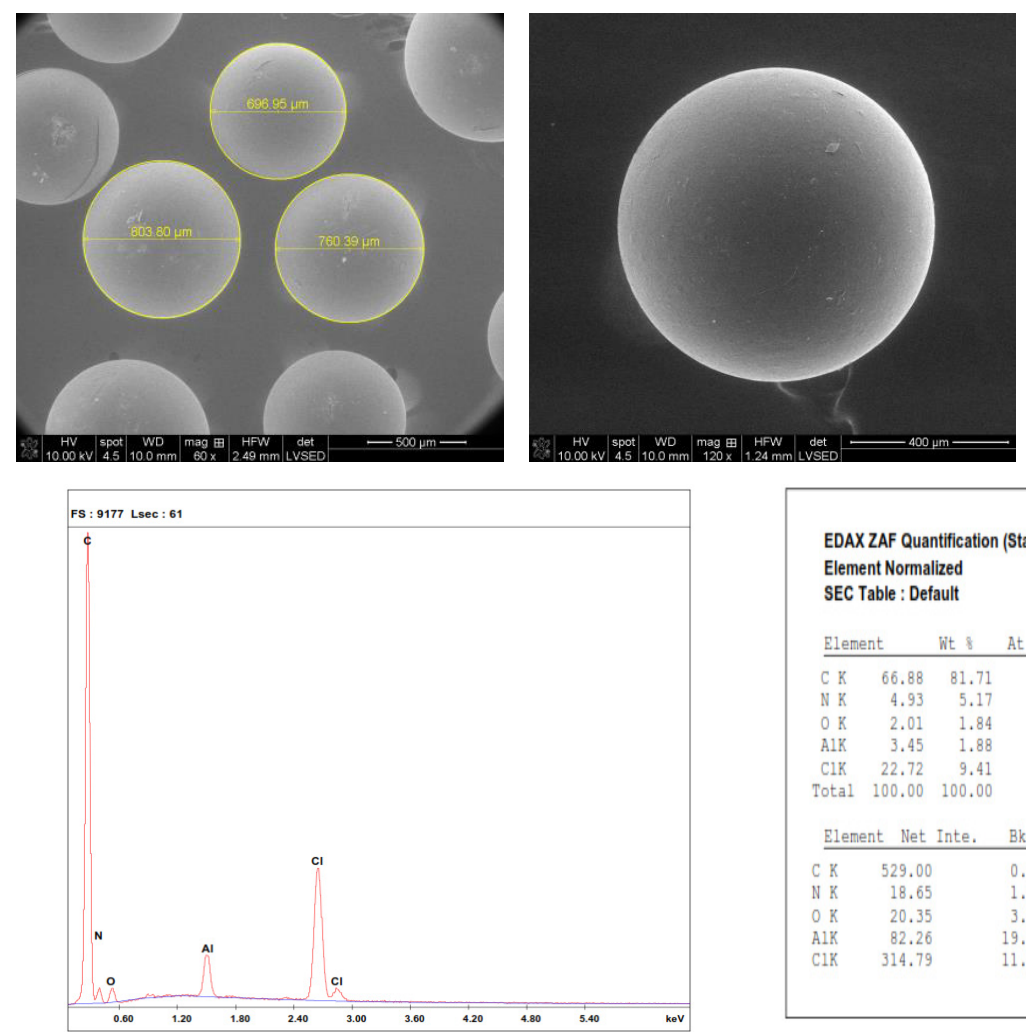
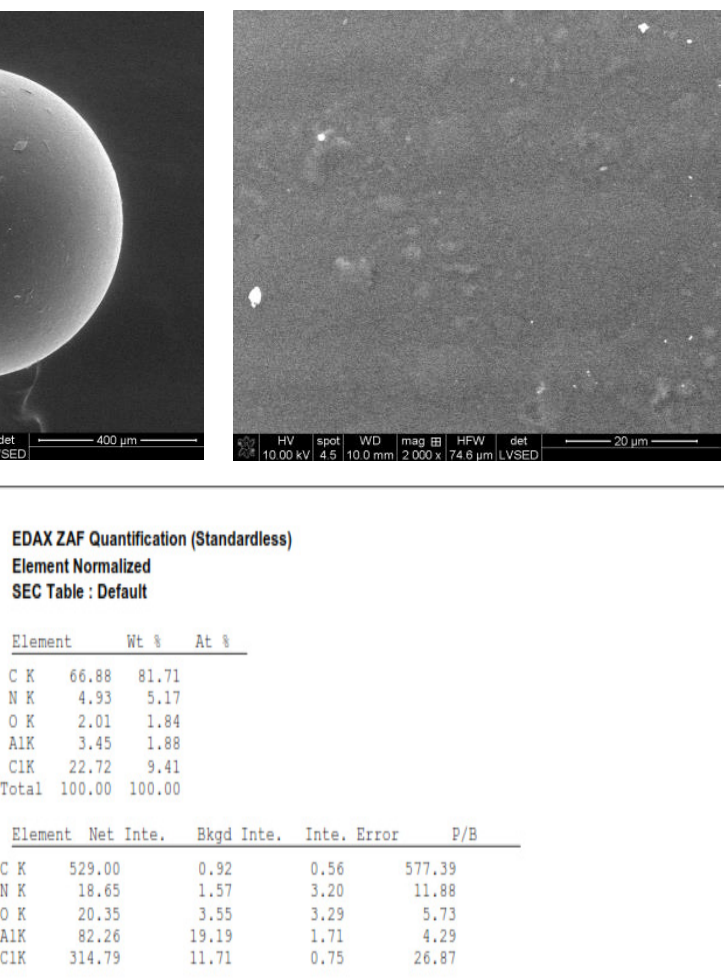

Fig. 7. SEM analysis of unultrasonated Purolite A600U/3472 resin - structure and composition.
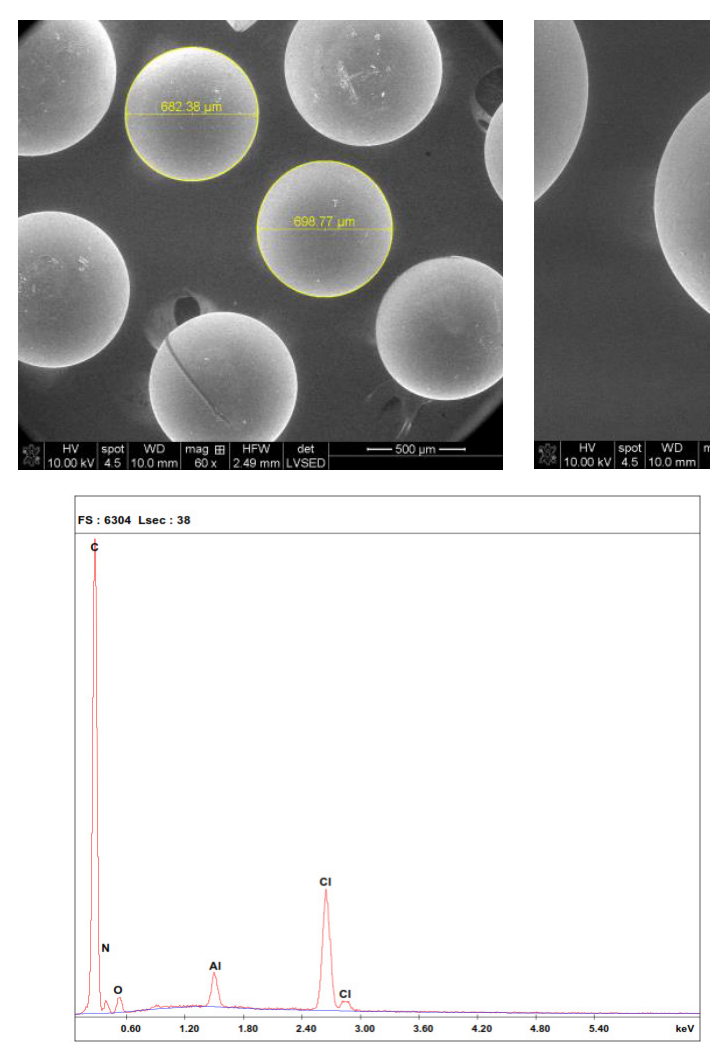
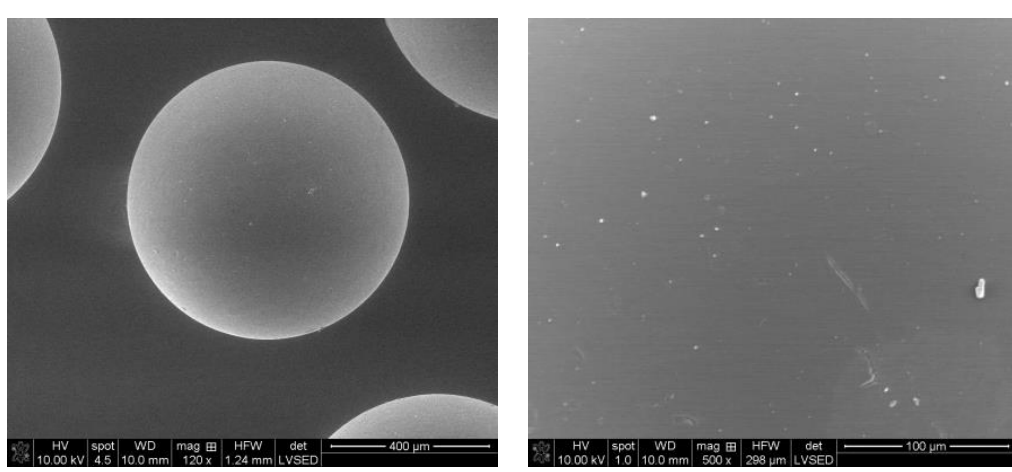

EDAX ZAF Quantification (Standardless)

Element Normalized
SEC Table : Default

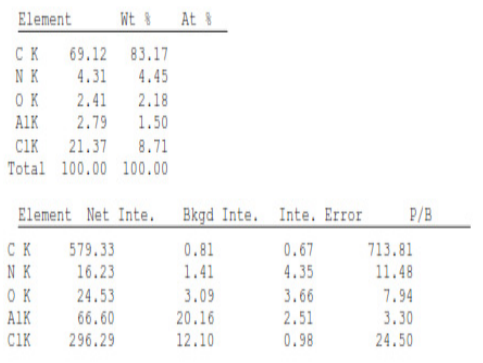

Fig. 8. SEM analysis of 6 hours ultrasonated Purolite A600U/3472 resin- structure and composition.

\footnotetext{
$\overline{\text { * Corresponding author: antonetafilcenco@yahoo.ro }}$
} 

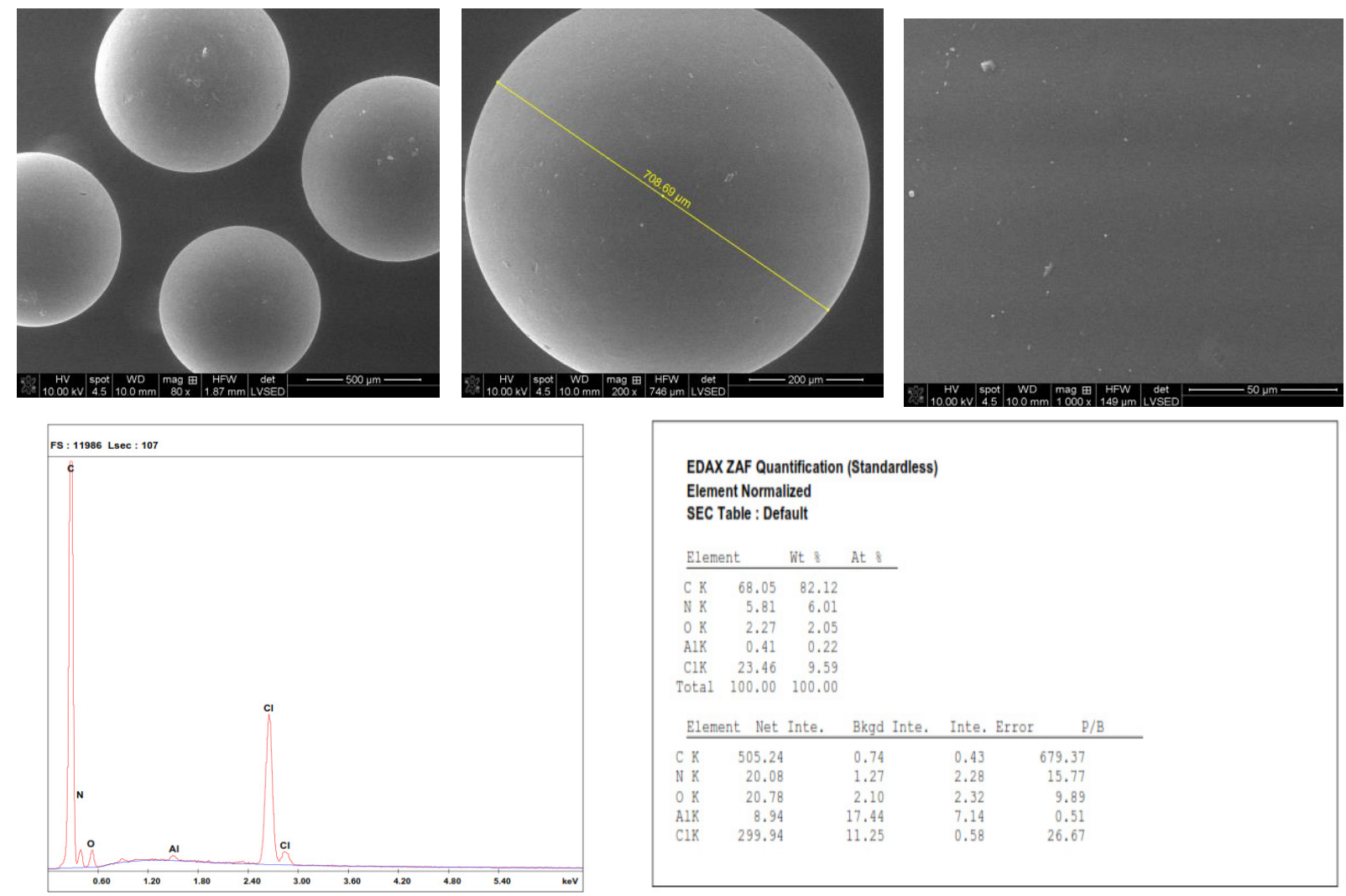

Fig. 9. SEM analysis of 18 hours ultrasonated Purolite A600U/3472 resin- structure and composition.
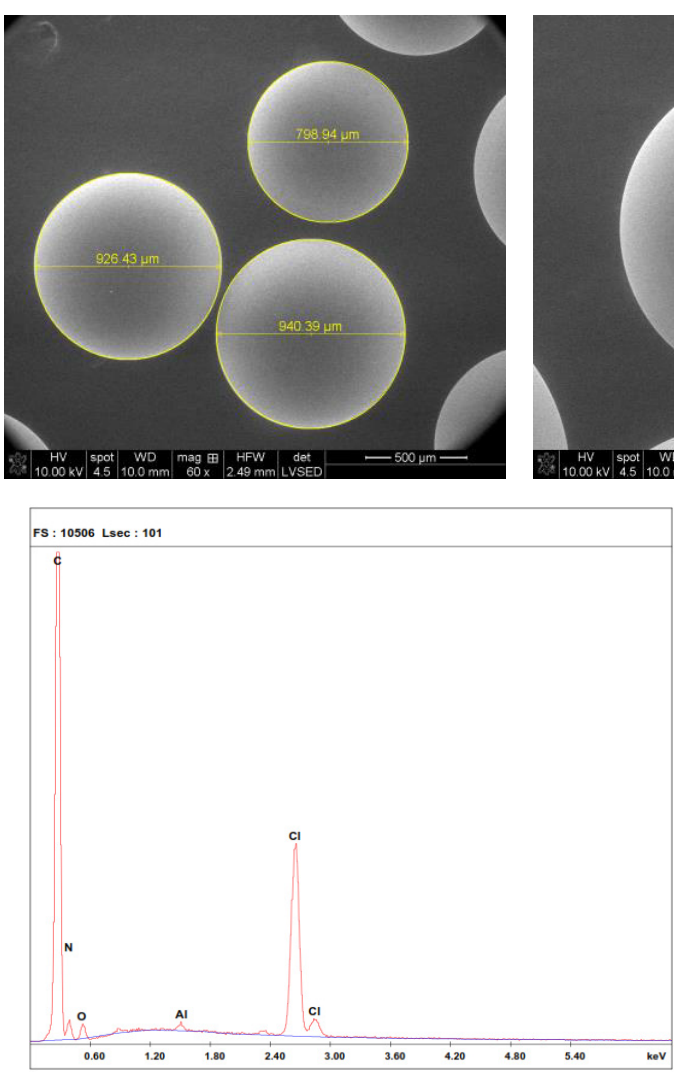
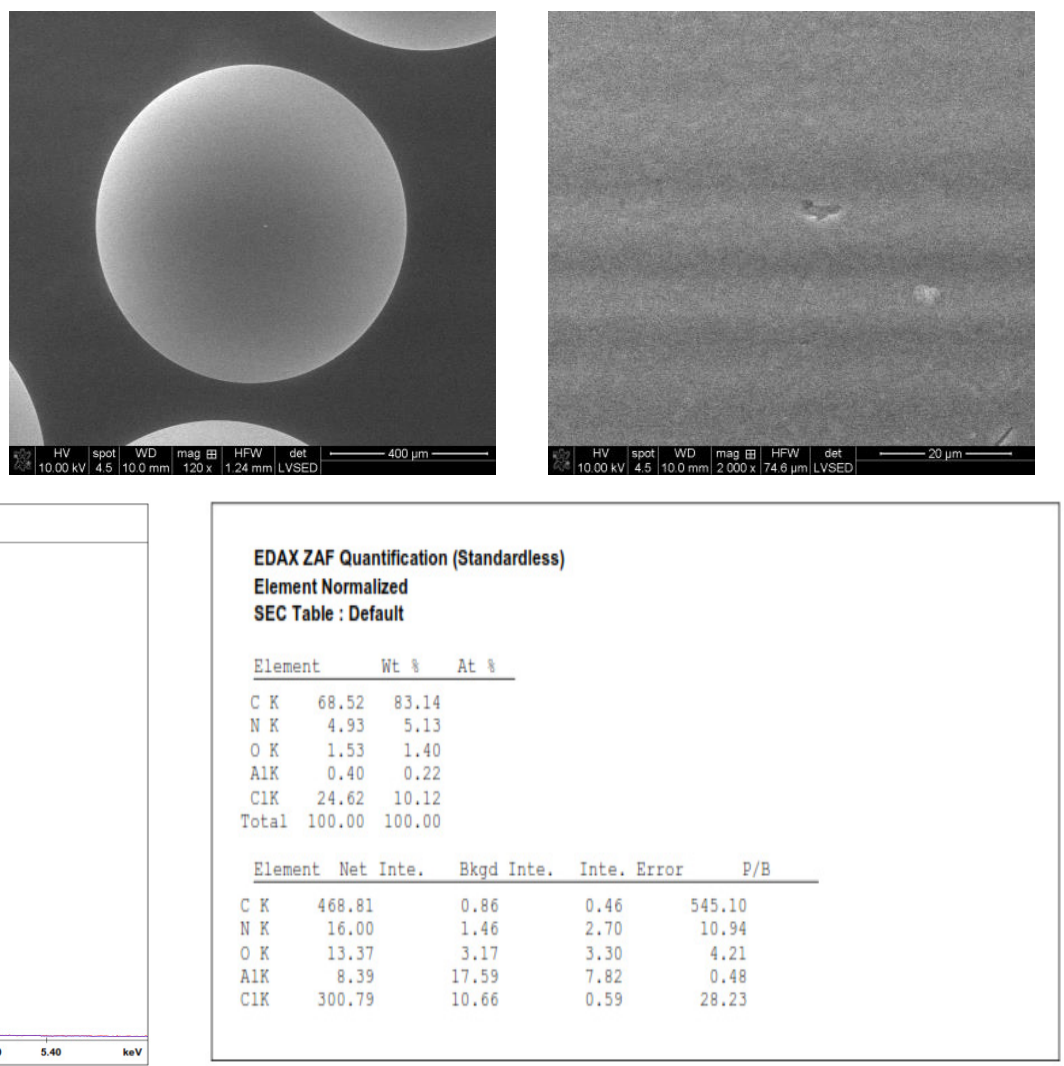

Fig. 10. SEM analysis of unultrasonated PM 11 resin - structure and composition. 

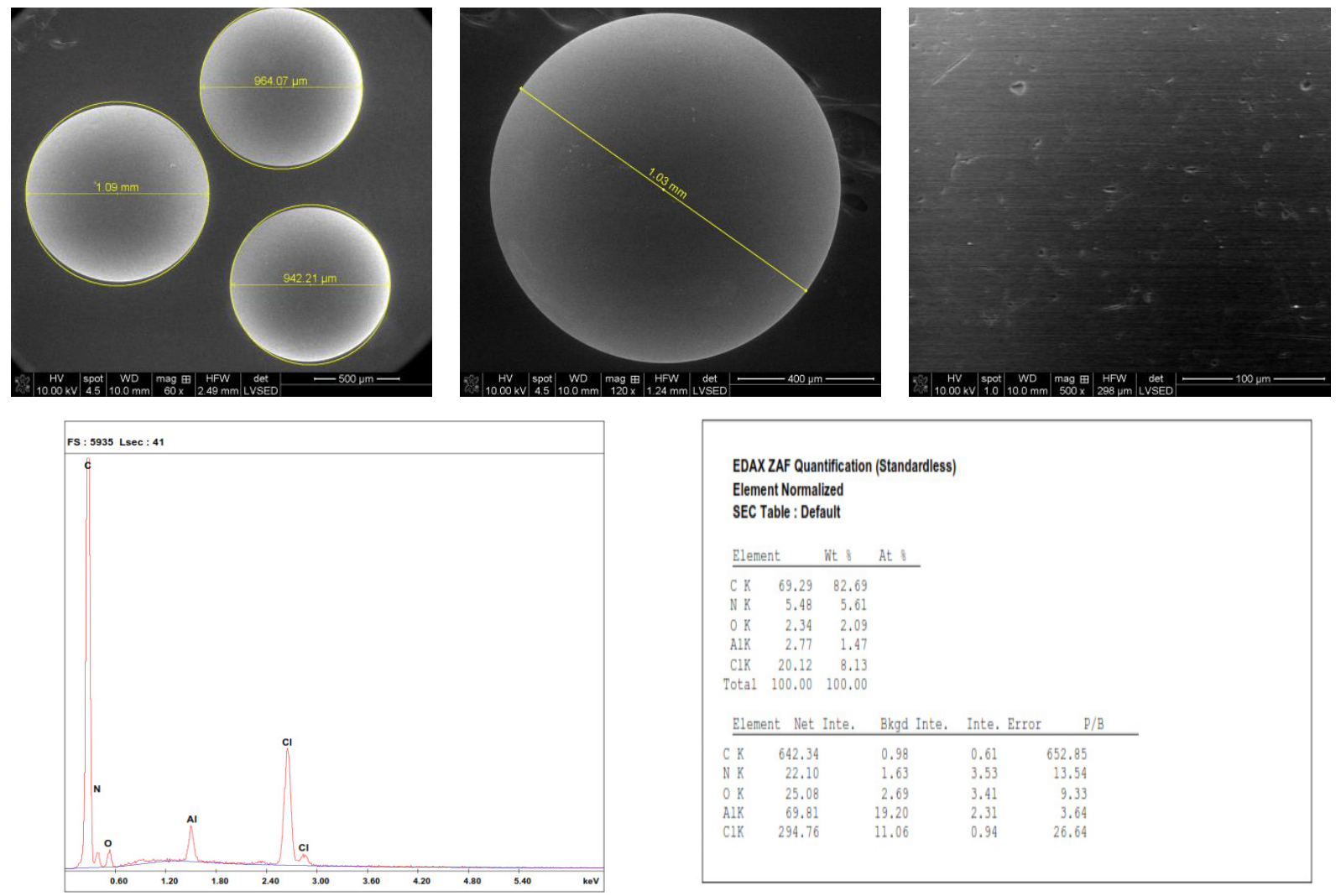

Fig. 11. SEM analysis of 6 hours ultrasonated PM 11 resin - structure and composition.
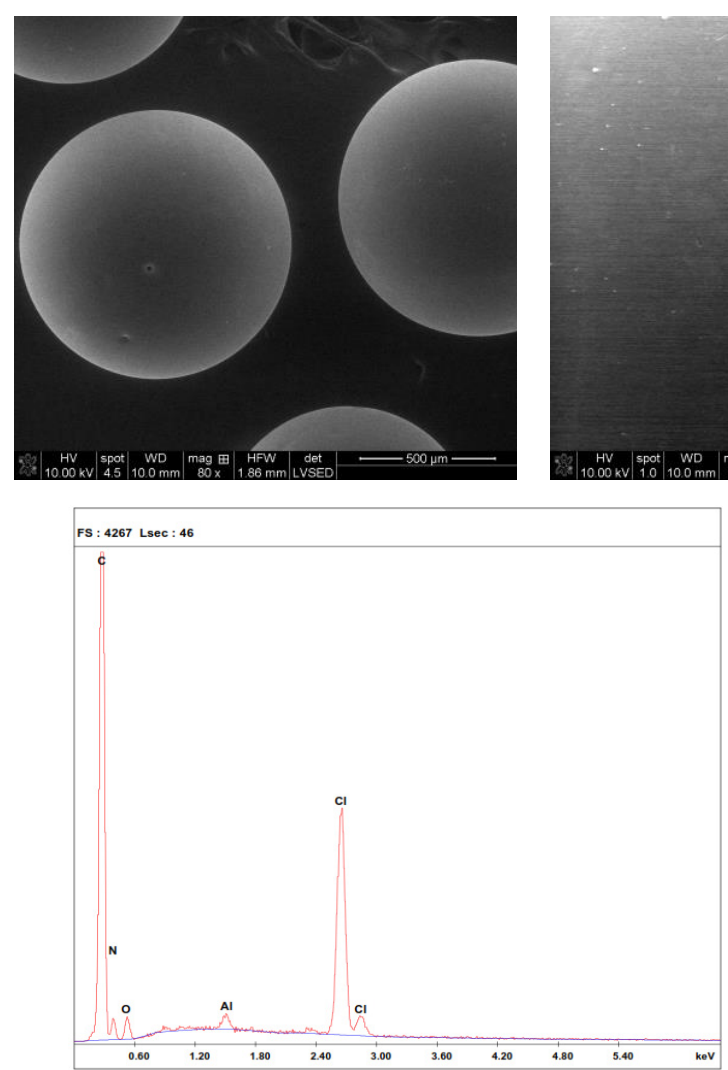
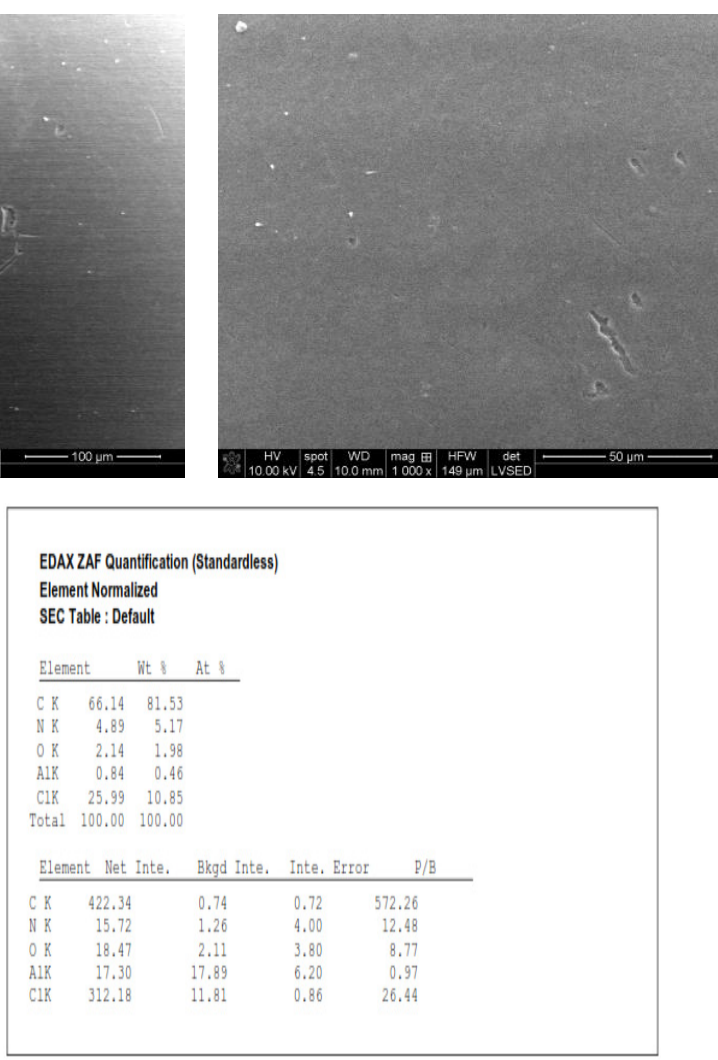

Fig. 12. SEM analysis of 18 hours ultrasonated PM 11 resin - structure and composition. 


\subsection{The influence of ultrasounds on the uranium loading capacity of the resins}

\subsubsection{The dynamics of uranium desorption from the anion-exchange resins Purolite A-600U/3472 and PM 611 without/with ultrasounds}

Since the adsorption/desorption operations are cyclical, it is important to know if applied ultrasound only on desorption operation influences the loading capacity of the ultrasounded resin compared with non-ultrasonated in the adsorption process.

Adsorption experiments performed in dynamic conditions, on the two types of ultrasounded resin for 18 hours in similar conditions with the initial adsorption experiment (non-ultrasounded resin), led to the results presented comparatively in Figures 13 and 14.

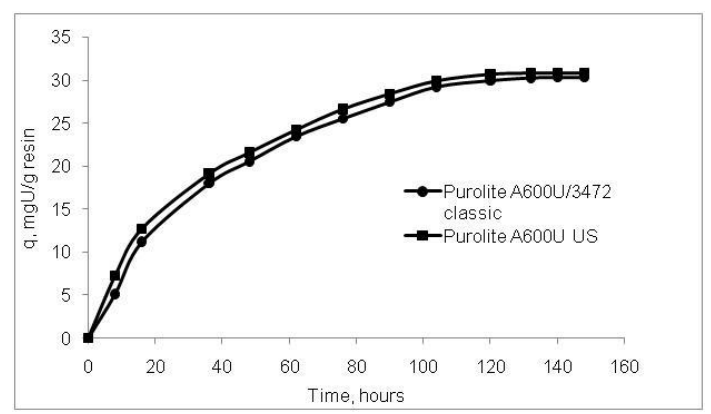

Fig. 13. Comparative evolution of uranium (VI) adsorption dynamics on Purolite A 600U/3472 resin previously untreated with ultrasound field and in the field of ultrasound for 18 hours (from solution with the following characteristics: $\mathrm{U}=35.37$ $\mathrm{mg} / \mathrm{L} \mathrm{Na} \mathrm{CO}_{3}=3.18 \mathrm{~g} / \mathrm{L}, \mathrm{NaHCO}_{3}=0.504 \mathrm{~g} / \mathrm{L}$ and $\mathrm{pH}=9.5$ ).

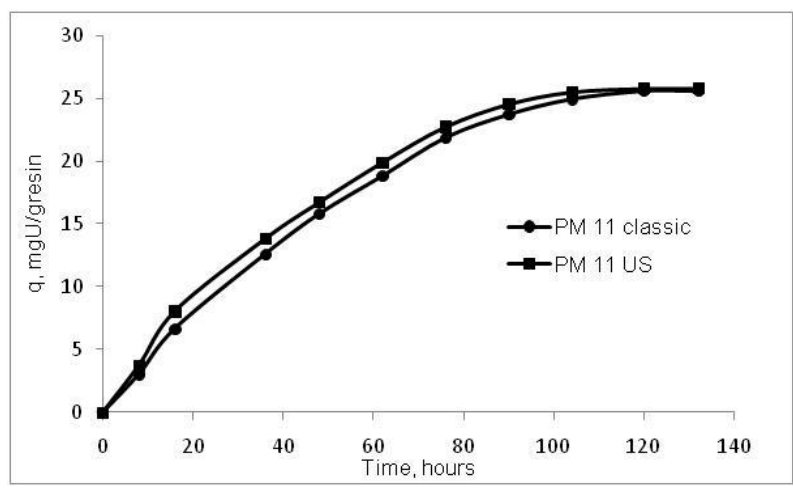

Fig. 14. Comparative evolution of uranium (VI) adsorption dynamics on PM 611 resin previously untreated with ultrasound field and in the field of ultrasound for 18 hours (from solution with the following characteristics: $\mathrm{U}=35.37 \mathrm{mg} / \mathrm{L}, \mathrm{Na}_{2} \mathrm{CO}_{3}=$ $3.18 \mathrm{~g} / \mathrm{L}, \mathrm{NaHCO}_{3}=0.504 \mathrm{~g} / \mathrm{L}$ and $\mathrm{pH}=9.5$.

The experimental results shown in Figures 13 and 14, emphasize the fact that ultrasounds do not affect the adsorptive properties of the resins, as the uranium loading capacity is basically similar.

The value of effective adsorption capacity of ultrasounded Purolite A- 600U/3472 resin was $30.85 \mathrm{mgU} / \mathrm{g}$ resin, compared with non-ultrasounded of
$30.36 \mathrm{mgU} / \mathrm{g}$ resin, and in case of $\mathrm{PM} 611$ resin the values are comparable also, respectively $25.79 \mathrm{mgU} / \mathrm{g}$ ultrasounded resin and $25.64 \mathrm{mgU} / \mathrm{g}$ non-ultrasounded resin

SEM analysis of the resin granules, reveals that their surface did not change significantly after ultrasonication, thus making the transfer area (grain size) to maintain the same initial limits. This would be the reason for the similar values of loading capacity of both situation studied.

It can be affirmed that ultrasounds do not affect the adsorptive properties of the resins studied and they can be used consecutively without special treatments in the adsorption - desorption process.

\section{Conclusions}

The desorption of the uranium complex ions from two ion-exchange resins Purolite A600U/3472 (Romania) and PM 611 (China), both in classic conditions and under the action of the ultrasonic field has been studied.

Uranium desorption in presence of continuous ultrasonic field is $99 \%$ with $3 \mathrm{BEV}$ of chloro-sodic solution, for two types of studied resins, while $7 \mathrm{BEV}$ in classical conditions. The difference between the two resins can be observed in the uranium content of effluent and in the recycled uranium, which is in favor of Purolite A600 U/3472 resin.

The ultrasound influence study on physical properties of the resins, on uranium loading capacities and SEM analysis demonstrated that it does not affect the adsorptive properties of resin.

The mass transfer intensification in desorption process is due to acoustics vortexes, which causes micro turbulences in the interiors of pores of the granule and the solid-liquid interface.

Application of ultrasound in the uranium desorption process has led to a decrease in the process`s duration and the decrease of desorption reagent volumes, which leads to an increase of the uranium content by $16 \%$ in the first two or three volumes of effluent that are going to precipitation and also to reduction of reagents costs by over $50 \%$.

\section{References}

1. Uranium extraction Technology Technical Reports, Series No. 359 IAEA (Vienna, 1993)

2. W. Holl, Fundamentals of Ion Exchange (Institute for Technical Chemistry, Karlsruhe,1997)

3. F. Dardel, T. V. Arden, Rohm and Haas Brochure, A(14) (1989)

4. C.E. Harland, Ion Exchange: Theory and Practice, (Royal Society of Chemistry, 1994)

5. T. Ionescu, Schimbul ionic în tehnică, (Editura Tehnică, Bucuresti, 1969)

6. A. Botez, T. Dobre, E. Panturu, A. Filcenco-Olteanu, Cent. Eur. J. Chem. 12 (7), 769-773 (2014)

*Corresponding author: antonetafilcenco@yahoo.ro 
7. F.T. Shostak, M. V. Vittikh, G. A. Savel'eva, G. S. Kozlov, L. S. Malinovskii, Akad. Nauk Kaz. SSR, Tr. Resp. Soveshch., 43-45 (1963)

8. K.L. Cheng, Zenpu Wang., Microchim. 78, 399406(1982)

9. A.S. Medvedev, V.V. Puchkov, N.N. Khavskii, R.G. Surukhanov, I.I. Tarasova, G.A. Evgrafova, Izv.Vyssh. Uchebn. Zaved. Tsvetn. Metall. (1986)

10. B.A. Agranat, M.A. Dubrovin, N.N Khavskii, G. Eskin, Basics of Physics and Technique of Ultrasound (Vysshaya Shkola, Moscow, 1987)

11. O. Tetsuo, J. Chromatogr. A 793, 365-369 (1998)

12. D. Liu, I. Aoyama, H. Okamura, B.I. Dutka, Toxicol. Water Qual., 11, 195-200 (1996),

13. S. Mukherjee, R. Matthew, H.N. Hsieh. Geotech. Spec. Publ., ASCE, 65, 122 (1997)

14. A.P. Newman, J.P. Lormer, T.J. Mason, K.R. Hutt, Ultrason. Sonochem, 4, 153-156 (1997)

15. W. Qin, Y. Yuan, Y. Dai, Chem. Ind. Eng. Soc., II, 600 (1997)

16. S.U. Rege, R.T. Yang, C.A. Cain, 44, 1519-1528 (1998)

17. I. Küncek, S. Şener, 17, 250-257 (2010)

18. M. Roosta, M. Ghaedi, A. Daneshfar, R. Sahraei, A. Asghari, Ultrason. Sonochem., 21, 242-252 (2014)

19. A. Vildan Beşe, Ultrason. Sonochem.,10, 790-796 (2007)

20. F. Xie,L. Haiying, M. Yang,L. Chuncheng, C. Tingting, H.Zhiyuan, Y.Gaoqing, J. Hazard. Mater. 170, 430-435 (2009)

21. L. Chuncheng, X.Fengchun,M. Yang,C. Tingting,L. Haiying, H. Zhiyuan,Y. Gaoqing, J. Hazard. Mater. 178, 823-833 (2010)

22. J.M. Timothy, S.S. Phull, M. Sternagel, J.P. Lorimer,B. Pollet, Ultras. in Environm. Eng., 25, 181 (1999)

23. B.G. Pollet, R. Viennet, J.Y. Hihn, J.Y. Doche, J.P. Lorimer, T.J. Mason, Hydrodynamic and Mass Transfer behaviour near the Ultrasonic Horn at Low Frequencies, Applications of Power Ultrasound in Physical and Chemical Processing Conference (Paris, 2001)

24. B. Pollet,S.S. Phull, J.P. Lorimer,T.J. Mason, The Use and Applications of Ultrasound in Environmental Protection - Environmental Sonochemistry,S.E.T. '99 at the House of Commons - Young Research Scientists, Engineers and Technologists,(1999)

25. J.M. Timothy, F. Doust, L. Paniwnyk,B. Pollet, Mass transfer measurements at small electrodeultrasonic horn separations, 10th Meeting of the European Society of Sonochemistry (Hamburg, 2006)

26. T.J. Mason, J.P. Lorimer, L. Paniwnyk,B. Pollet, Mater World, 7(2) (1999)
27. A.D., Radu, A. Woinaroschy, E. Panturu, Rev. Chim., 65(4) 470-474 (2014)

28. E. Panturu, Ghe. Jinescu, R. Radulescu, A. Filcenco Olteanu, C. Jinescu, Rev. Chim. 59(9) 1036-1040 (2008)

29. W. Xue Jiang,J. Chen,Yl. Xiangbo,Xl. Wang,J. Zhang,J. Huang,J. Zhao, J. Ind. Eng. Chem. (2015)

30. E. Panturu, Method acid extraction of uranium from ore in ultrasonic field-Patent No. 122642 (2009)

31. W.C. Kyeong, J.K. Chul, H.S. Yoo, Highly efficient uranium leaching method using ultrasound, US Patent N0.: 8,470,269 B2 (2013)

32. Process intensification of chemical decontamination of radioactively contaminated soils using ultrasound, Patent No. 123554/08 (2013)

33. D. Feng, C. Aldrich, Hydrom., 55, 201-212 (2000)

34. E. Panturu, Ghe. Jinescu, F. Aurelian, R. Rădulescu, A. Filcenco-Olteanu, Rev.Chim., 58(6) 551-556 (2007)

35. K. Aneel, J. Takemura, Int. J. Env. Sci. Devel. 1, 3, 260-263 (2010)

36. D. Feng, H. Tan, J.S.J. van Deventer, Miner. Eng., 16(3), 257-264 (2003)

37. J.K. Chul, W.C. Kyeong, H.S. Yoon, Sonochemical ion exchange in RIP system, ALTA, Uranium Conference 97 (2011)

38. D. Chen, S.K. Sharma, A. Mudhoo, Handbook of application of ultrasound: sonochemistry for sustainability, CRC Press (2011)

39. T.J. Mason, D. Peters, Practical Sonochemistry. Power Ultrasound Uses and Applications, Ellis Horwood Publishing Limited (2002)

40. M. Breitbach,D. Bathen,H. Schmidt-Traub, Ind. Eng. Chem. Res., 42(22), 5635-5646 (2003)

41. W.B.Zhang,M. Deng,C.X. Sun,S.B. Wang,. Eng. Chem. Res., 53(1), 333-339 (2014)

42. E. Panturu, Method of optimizing the uranium desorption from ion exchange resins under the effect of ultrasound, No.brevet 122767 (2010)

43. J. K. Youngs, Solvent extraction process, US 5463177 A (1995)

44. B.Pesic, Technical Report: Application of ultrasound in solvent extraction of nickel and gallium, Contract DE-AC07-941D13223, Interior Department's Bureau of Mines and US Department of Energy, Idaho, 78 (1996)

45. X.P. Chen, W.X. Wang, S.B. Li, J.L. Xue, L.J. Fan, Z.J. Sheng, Y.G. Chen,. Polym. 80, 944-948 (2010)

46. M. Sillanpää, T.D. Pham, R.A. Shrestha, Ultrasound Technology in Green Chemistry, (Springer, 2011)

47. M. Bimakr, R.A. Rahman, F.S. Taip, N.M. Adzahan, Z.I. Sarker, A. Ganjloo, Molecules, 17, 11748-1176 (2012)

48. T. Li, X.Y. Qu, Q.A. Zhang, Z.Z. Wang, Ind. Crop. Prod. 35, 98-104 (2012) 
49. A. Balasubrahmanyam, S.B. Roy,S. Chowdhury, K.N. Hareendran, A.B. Pandit, , Ind. Eng. Chem. Res 45(22), 7639-7648 (2006)

50. P.K. Kalsi, B.S. Tomar,K.L. Ramakumar,V. Venugopal, Journal of Radioanal. Nucl. Chem., 293, 863-867 (2012)

51. A.Balasubrahmanyam, S.B. Roy,Y. Ladola, S. Chowdhury, K.N. Hareendran, A. B. Pandit, Chem. Eng. Proces.: Process Intens., 47, 2107-2113 (2008)

52. R. Bikram, S. Bhattacharya, S.B. Roy, Int. J. Nucl. Energy Sci. Techn., 8, 171-178 (2014)

53. O. Hamdaoui, E. Naffrechoux, AIChE Journal 53, 363-373 (2007)54
54. K.W. Chung, C.J. Kim, H.S. Yoon, Uranium ion exchange adsorption method using ultrasound, S Patent 8,475,746 B2 (2013)

55. EPA (U.S.Environmental Protection Agency), Understading variation in partition coefficient, values, Vol I, The Kd model, methods of measurement, and application of chemical reaction codes, EPA 402-R-99-004A, U.S. Environmental Protection Agency, Washington D.C (1999)

56. A. Balasubrahmanyam, S.B. Roy,S. Chowdhury, K.N. Hareendran, A.B. Pandit, Ind. Eng. Chem. Res., 45(22), 7639-7648 (2006)

57. P.K. Kalsi,B.S. Tomar,K.L. Ramakumar, V. Venugopal, Journal of Radioanal. Nucl. Chem., 293, 863-867 (2012) 